\title{
Sediment and Shallow Coastal Water Detection Utilizing MODIS Land Channels over Gulf of Martaban
}

\author{
Abd Rahman Mat Amin \\ Faculty of Applied Science, Universiti Teknologi Mara, Kuala Terengganu \\ 21080 Kuala Terengganu, Terengganu, Malaysia \\ Tel: 609-617-5255 E-mail: abdra401@tganu.uitm.edu.my
}

Khiruddin Abdullah

School of Physics, Universiti Sains Malaysia, Minden, 11080 Pulau Pinang, Malaysia

Tel: 604-653-2477Ｅ-mail: khirudd@usm.my

\begin{abstract}
Application of clear waters (Case 1) algorithm to satellite imagery acquired with Moderate Resolution Imaging Spectroradiometer (MODIS) over turbid coastal waters (Case 2) often results in negative water-leaving radiances over extended areas. Also, the maximum reflectances for ocean color channels are significantly smaller than those for the land channels at similar wavelengths. Because of that, at the bright coastal water areas, ocean color channels $(0.488,0.531$ and $0.551 \mu \mathrm{m})$ often saturate. The saturation of these channels will contribute to the lost of geophysical and biological activities in the data. So, in order to overcome this circumstance, it is reasonable to use MODIS land and atmosphere channels ( 1 to 7 ) to derive an algorithm for the detections of turbid and shallow coastal water areas. In order to improve chlorophyll retrieving algorithm over the ocean, an algorithm to mask out the turbid coastal water area needs to be developed. In this paper, a simple algorithm to identify and mask shallow coastal water and high amounts of suspended sediment area in the Gulf of Martaban using MODIS L1B image is suggested and demonstrated. This algorithm uses $\log _{10}$ ratio of two MODIS solar channels originally designed for remote sensing over land and cloud properties centered at 0.47 and $0.55 \mu \mathrm{m}$ (bands 3 and 4 respectively). Shallow coastal water and the area with high amount of suspended sediment detected by our algorithm were then masked. The result of this algorithm was then evaluated by comparing each masked area with the corresponding mask generated by using other established technique.
\end{abstract}

Keywords: Remote sensing, MODIS, Turbid coastal waters, Sediment

\section{Introduction}

The atmospheric correction algorithm for Moderate Resolution Imaging Spectroradiometer (MODIS) uses aerosol information derived from sensor-measured two near-infrared (NIR) bands and then extrapolates it into visible wavelengths through evaluation of the aerosol parameter (Yu et al., 2006; Levy et al., 2007). The ocean at the two NIR bands (748 and $869 \mathrm{~nm}$ for MODIS) is usually assumed to be black in order to effect the atmospheric correction and derive aerosol properties. However, for the turbid ocean waters, ocean could have significant contributions at the NIR bands, leading to an overestimation of aerosol contributions and an underestimation of the derived water-leaving reflectance in the visible (Wang and Shi, 2005). The ocean color images, as routinely processed by several space agencies, often show red color (a color encoding attributed to very high chlorophyll concentration) along many coasts of the world ocean and particularly in semi-enclosed seas (Morel and Belanger, 2006). Even if there are some good reasons to expect sizeable enhancements of the algal biomass in these shallow zones (because of a possible nutrient influx from terrestrial origin, and/or rapid recycling of nutrients), it is also known that the algorithms (of the blue-to-green ratio type) developed for open ocean waters fail in such zones, with the result of strongly overestimating chlorophyll (Morel and Belanger, 2006; Morel and Prieur, 1997). Due to this uncertainty, turbid area along coastal (Case 2) waters needs to be clearly distinguished from open ocean region (Case 1) waters.

The fact that suspended sediments increase the radiant emergent from surface waters in the visible and near infrared region of the electromagnet spectrum has been made since late 1970's (Ritchie et al., 1976). Most researches that had a large range (i.e., 0-200 $\mathrm{mg} \mathrm{l}^{-1}$ ) of suspended sediment concentration have found a 
curvilinear relationship between suspended sediments and radiance or reflectance (Ritchie et al., (1976); (1990); Curran et al., 1988). This is because the amount of reflected radiance tends to saturate the respected channels used for detection as suspended sediment concentrations increase. The point of saturation is wavelength dependent, with the shorter wavelength channels saturating at lower concentrations (Ritchie and Cooper, 1988).

Numerous investigators have established an empirical relationship between reflected solar radiance measured by remote sensing instruments with suspended sediments in a wide range of inland and coastal waters. $\mathrm{Li}$ et al. (2003) have developed an algorithm to detect sediment dominated water using MODIS measurements at the SWIR and green bands. While Morel and Belanger (2006) have refined the scheme using normalized water leaving radiance $(\mathrm{nLw}(\lambda))$ threshold value at the green band for the turbid water detection. Wang and Shi (2005) use the combinations of the MODIS measured radiances at the short visible, NIR, and SWIR bands. Another method was developed by Figueras et al. (2004) by using a null point at 497nm (corresponding to SeaWiFS band 4 centered at $510 \mathrm{~nm}$ ) where the level of reflectance is not affected by change in chlorophyll concentration.

In this paper we propose a simple algorithm to identify shallow coastal water and high amounts of suspended sediment area. This simple algorithm is based on the $\log _{10}$ ratio of 0.47 and $0.55 \mu \mathrm{m}$ channels. We will describe the development of the algorithm through example. We present sample results from applications of our algorithm to several MODIS datasets acquired over the Gulf of Martaban. Shallow coastal water and the areas with high amount of suspended sediment detected by our algorithm were then masked and compared with the masks produced by the algorithm proposed by Li et al. (2003).

\section{Ocean contributions at the MODIS visible channels}

Moderate Resolution Imaging Spectroradiometer (MODIS) was launched aboard Terra in late 1999 and aboard Aqua in early 2002. MODIS data have been used to answer scientific questions about radiation and climate (Yu et al., 2006; Levy et al., 2007). The MODIS instruments aboard both Terra and Aqua measure spectral radiance in 36 channels, in resolutions between $250 \mathrm{~m}$ and $1 \mathrm{~km}$ (at nadir). In polar orbit, approximately $700 \mathrm{~km}$ above the Earth, MODIS views a swath $2300 \mathrm{~km}$, results in near daily global coverage of Earth's land, ocean and atmosphere system.

MODIS channels 1-7 in the 0.4-2.3 $\mu \mathrm{m}$ region are designed for remote sensing over land and atmosphere. Meanwhile, channels 8-16 in the 0.4-0.9 $\mu \mathrm{m}$ spectral range are mainly designed for clear water (Case 1) remote sensing (Li et al., 2003). The maximum reflectances for ocean color channels are significantly smaller than those for the land channels at similar wavelengths. Because of that, at the bright coastal water area, ocean color channels $(0.488,0.531$ and $0.551 \mu \mathrm{m})$ often saturate ( $\mathrm{Li}$ et al., 2007). Table 1 shows the characteristics of the MODIS channels ( $\mathrm{Li}$ et al., 2007; King et al., 1992). However, the ocean color channels have much higher signal-to-noise ratios and sensitive to darker surface compared to the land channels centered at similar wavelength. MODIS channels 1 to 2 also channels 3 to 7 with initial resolution $250 \mathrm{~m}$ and $500 \mathrm{~m}$ respectively have been aggregated to $1 \mathrm{~km}$ resolution in MODIS L1B product. Although MODIS channels 1 to 7 are designed for remote sensing over land and atmosphere, it also has applications for remote sensing of coastal water and inland waters ( $\mathrm{Li}$ et al., 2007).

Over Gulf of Martaban, ocean waters are very turbid all the season. Figure 1(a) provides a true color composite image (red: channel 1, green: channel 4, blue: channel 3) observed by MODIS Terra over the Gulf of Martaban for the date of 22 November 2008. The original spatial solution for land channels 1, 4 and 3 are 250,500 and 500 $\mathrm{m}$ respectively. The image was degraded to the $1 \mathrm{~km}$ resolution of ocean color channels. This image shows very turbid waters along the gulf and demonstrates significantly high concentrations of suspended sediment (grayish-yellow ocean waters).

Figure 1(b) illustrates a color composite image acquired over the same scene and date, but for ocean color channels (red: channel 14, green: channel 12, blue: channel 10) at a spatial resolution of $1 \mathrm{~km}$. Many of the spatial features observed with the imagery produced from the land channels such as the shallow sediment banks cannot be observed with the ocean channels, which saturate over bright coastal water surface. As mentioned above, due to high maximum reflectance for land channels, an increase in reflectance over turbid area will not saturate any of these channels. As an example, the highest reflectance of red, green and blue channels over the Gulf of Martaban for the date 22 November 2008 are $0.14,0.15$ and 0.16 respectively. However, these reflectance values already exceed the maximum reflectance (red: 0.07 , green: 0.12 , blue: 0.17 ) for ocean channels. The saturation of this channels contributes to the lost of geophysical and biological activities in the data. So, in order to overcome this circumstance, it is reasonable to use MODIS land and atmosphere channels (1 to 7) to derive an algorithm for the detections of turbid and shallow coastal water areas.

The studies of apparent reflectance spectra show that, the main differences between the Case 1 and Case 2 water 
are located in the 0.4-0.7 $\mu \mathrm{m}$ channels where the turbid water has significantly larger reflectance than the clear water ( $\mathrm{Li}$ et al., 2003; Reza, 2008). There are three MODIS channels that are located within this range, 0.47, 0.55 and $0.66 \mu \mathrm{m}$. The blue channel $(0.47 \mu \mathrm{m})$ has been found to be very sensitive to atmospheric molecular scattering, but less sensitive to the additional reflection by sediments (Li et al., 2003; Reza, 2008). Furthermore, over turbid coastal waters, this channel is not as sensitive as the $0.55 \mu \mathrm{m}$ channel to sediment reflection because of strong absorption by dissolved organic matters. Our studies indicated that the $0.47 \mu \mathrm{m}$ channel reflectance only shows a slight increment over turbid water compared to the 0.55 and 0.66 channels. Also, in this case study, both the $0.55 \mu \mathrm{m}$ and the $0.66 \mu \mathrm{m}$ channels can, in principle, be used for sediment detections according to high reflectance increment in these two channels over coastal area with high sediment concentration. But, the $0.55 \mu \mathrm{m}$ channel can sense far deeper into the ocean than the $0.66 \mu \mathrm{m}$ channel because of much smaller liquid water absorption at $0.55 \mathrm{~m}$ than at $0.66 \mu \mathrm{m}$ (Mobley, 1994). Furthermore, $0.55 \mu \mathrm{m}$ channel can penetrate about $40 \mathrm{~m}$ under the very clear water surface ( $\mathrm{Li}$ et al., 2003). The high penetration power of $0.55 \mu \mathrm{m}$ channels made this channel more suitable to detect bottom reflectance of the shallow coastal water. Because of the reflectance of $0.47 \mu \mathrm{m}$ is only slightly influence by the sediment and the ability of $0.55 \mu \mathrm{m}$ channel to sense the present of sediment and bottom reflectance, compared to the $0.66 \mu \mathrm{m}$ channel that has shallower water penetration, the 0.47 and $0.55 \mu \mathrm{m}$ channels can be utilized to detect bottom reflectance and turbid area over bright coastal waters.

\section{Data and study area}

MODIS Terra Level 1B (MOD021KM) during the period of January 2008 to December 2008 have been used in this study. The study area covers roughly the latitude range of $11^{\circ} \mathrm{N}-18^{\circ} \mathrm{N}$ and the longitude range of $93^{\circ} \mathrm{E}-99^{\circ} \mathrm{E}$. The MODIS Level 1B granule consists of calibrated radiances or reflectance. The product can be downloaded from website: $\mathrm{http}: / /$ ladsweb.nascom.nasa.gov/browse_images /12_browser. Html. Gulf of Martaban is located at the northern Andaman Sea. Annually more than 350 million tons of sediment deposited into this area by the Ayerrarwady, Salween and Sittang rivers. Seafloor in the Gulf of Martaban and adjacent inner shelf is generally smooth whereas the outer shelf has a rough surface with relief of 2-20 m and has topographic features such as pinnacles, highs and valleys, buried channels and scarps (Ramaswamy et al., 2004). In general, the Andaman Sea is a body of water to the southeast of the Bay of Bengal, south of Myanmar, west of Thailand and east of the Andaman Islands; it is part of the Indian Ocean. It is roughly $1,200 \mathrm{~km}$ (north-south) and $650 \mathrm{~km}$ wide (east-west), with an area of $797,700 \mathrm{~km}^{2}$. Its average depth is $870 \mathrm{~m}$, and the maximum depth is $3,777 \mathrm{~m}$. Surface suspended sediment concentrations (SSC) values in the Gulf of Martaban can be from less than $0.1 \mathrm{mg}$ $\mathrm{l}^{-1}$ to over $500 \mathrm{mg}^{-1}$ (Ramaswamy et al., 2004). Figure 2 below shows the map of the study area.

\section{Methodology}

In this paper, we propose a simple method to detect and mask sediment area for MODIS product based on the apparent reflectance of 0.47 and $0.55 \mu \mathrm{m}$ wavelengths. Any increment of the $0.55 \mu \mathrm{m}$ reflectance in the turbid water areas indicates the presence of sediment or shallow water. Meanwhile, the $0.47 \mu \mathrm{m}$ is influenced mainly by aerosol in the atmosphere and is slightly affected by sediment (Li et al., 2003). We have constructed an algorithm based on the reflectance characteristics of 0.47 and $0.55 \mu \mathrm{m}$ channels as mentioned above. The ratio of $\log _{10}$ of $0.47 \mu \mathrm{m}$ channels over $0.55 \mu \mathrm{m}$ channel can detect the clear and turbid water areas efficiently. A threshold has been used to discriminate these two areas. The thresholds have been obtained from the histogram of the reflectance in the study area. Any value that is above this threshold will be indicated as sediment and shallow water areas. To discard the land area from the imagery, NDVI algorithm have been used, whereas if the NDVI > 0.1 then that area is considered as land. The presence of cloud could also contribute to a significant error to this study. To ensure that the areas chosen are cloud free scenes, MODIS cloud mask algorithm for daytime over ocean region has been used. To evaluate the result of the algorithm, the masked region containing sediment and shallow coastal water retrieved by our algorithm was then compared to the region masked by Li et al. (2003) proposed algorithm.

\section{Result and discussion}

In this paper we describe the development of the algorithm through some examples. Figure 1 above shows an example of image taken for this study. Fifteen areas were selected and categorized based on visual inspection according to their conditions. Areas 1 to 5 are less turbid and are referred as clear water area. Areas 6-10 are visually influenced by aerosol and are referred as hazy area. They have higher reflectance value than those in area 1 to 5 . They are located in deep water region (depth greater than $40 \mathrm{~m}$ ) where the reflectance effects from sediment and bottom material were very small. Therefore these high reflectance water pixels are mainly caused by aerosol. The corresponding aerosol optical thickness (AOT) map (MODIS Level 2) distributed by Seadas also indicates the presence of aerosol (AOT values 0.100 to 0.310 ) in these areas. Meanwhile, areas 11-15 are 
visually turbid water areas with suspended sediment. Figure 3(a) below shows the comparisons between the spectral properties of clear water regions with and without aerosol contribution. A plot of the $\log _{10}$ reflectance as a function of $\log _{10}$ wavelength for clear water from areas 1 and 6 is shown in Fig. 3(a). Note that area 6 is influenced more by the haze aerosol than area 1 . The $\log _{10}$ reflectance values at 0.47 and $0.55 \mu \mathrm{m}$ from area 6 are higher than the corresponding values in area 1 . As an example, for the area 1 the $\log _{10}$ of $0.47 \mu \mathrm{m}$ is -1.05 and $\log _{10}$ of $0.55 \mu \mathrm{m}$ is -1.35 . For area 6 , the $\log _{10}$ of 0.47 and $0.55 \mu \mathrm{m}$ reflectance values are -0.94 and -1.19 respectively. If the reflectance value of $0.47 \mu \mathrm{m}$ increases with a small value, then the $0.55 \mu \mathrm{m}$ reflectance also increases accordingly so that the $\log _{10}$ ratio value of these two channels remains unchanged. This is also true if an increment is only in small value. Table 2 shows the reflectance values of 0.47 and $0.55 \mu \mathrm{m}$ bands for the test areas. As displayed along the $\log _{10}(0.47) / \log _{10}(0.55)$ column, the ratio values are nearly constant for clear and hazy conditions. Their values are around 0.78 . However, these values increase to 0.90 for the sediment area.

Figure 3(b) shows a comparison between the spectral properties of regions with and without sediments. A plot of the $\log _{10}$ reflectance as a function of $\log _{10}$ wavelength for clear and turbid water areas is shown in Fig. 3(b). Note that, the reflectance values of $0.55 \mu \mathrm{m}$ channel in areas 12 and 13 are highest among others. The $0.55 \mu \mathrm{m}$ reflectance values in areas with and without sediment are clearly different. As an example, the values of $\log _{10}$ of $0.55 \mu \mathrm{m}$ for sediment free areas 1 and 2 are -1.07 and -1.02 respectively. Meanwhile the $\log _{10}$ value of $0.55 \mu \mathrm{m}$ reflectance for area 12 and area 13 increases to -0.85 and -0.83 respectively for turbid water areas. Similar results were also obtained for another clear water areas (areas 3,4 and 5) and turbid water areas (areas 11, 14 and 15). Table 2 below shows that, the log ratio values of these two channels in the sediment area are higher compared to the clear and hazy areas. The excess reflectance of $0.55 \mu \mathrm{m}$ channel is attributed to the back scattering of solar radiation by sediments.

The threshold value to differentiate areas having turbid water and bottom reflectance from clear water areas has been taken from the statistics of the $\log _{10}$ ratio. Statistical values obtained show that the clear water region and the turbid area can be differentiated clearly using histogram method. An example of the histogram computed from 22 November 2008 scene is shown in Fig. 4 which clearly displays the three water categories (clear, hazy, turbid). The threshold between Case 1 and Case 2 can be determined. After studying 12 months of MODIS imageries of the Gulf of Martaban, we suggest that 0.86 is taken as a threshold value to differentiate between Case 1 and Case 2 water areas. Values above this threshold will be assigned as turbid and shallow coastal water areas.

\section{Sample results}

Figure 5 below shows a true color image (red: channel 1, green: channel 4, blue: channel 3) and masked image processed from the MODIS collected data over Gulf of Martaban for 4 March 2008. Figure 5(b) clearly shows that the predicted turbid areas have been masked using our proposed algorithm. The river mouths have also been successfully masked. The accuracy of the algorithm was assessed by comparing images produced by our model with those generated using the model proposed by $\mathrm{Li}$ et al. (2003). Figure 6 shows an example of the image comparison derived from 8 February 2008 scene (latitude: $14^{0} \mathrm{~N}-18^{0} \mathrm{~N}$, longitude: $93^{\circ} \mathrm{E}-98^{0} \mathrm{E}$ ). Figure $6(\mathrm{a})$ shows a true color image meanwhile Fig. $6(\mathrm{~b})$ a mask image by $\log _{10}$ ratio algorithm. The result of Li et al., (2003) algorithm shows in Fig. 6(b). We calculated the percentage difference between the outputs of the two models. The results showed a good agreement of about $95 \%$ between them.

\section{Conclusion}

A simple algorithm to detect and mask sediment and shallow coastal water has been proposed. The method is based on analyses of MODIS dataset captured over the Gulf of Martaban. Reasonable results have been obtained. Hopefully this proposed method can overcome the band saturation and improve the detection of ocean parameters such as chlorophyll and normalized water leaving radiance in marine environment of the Gulf of Martaban.

\section{Acknowledgment}

We would like to thank UiTM Kuala Terengganu and USM managements for the support and encouragement. Our appreciation to MODIS support team for all the valuable data provided.

\section{References}

Curran, P. J. and Novo, E. M. M. (1988). The Relationship between Suspended Sediment Concentration and Remotely Sensed Spectral radiance. A Rev. J. Coastal Res., 4: 351-368.

Figueras, D., Karnieli, A., Brenner, A. and Kaufman, Y. J. (2004). Masking turbid water in the southeastern Mediterranean Sea utilizing the SeaWiFS $510 \mathrm{~nm}$ spectral band. Remote Sens. Environ., 102, 237-249. 
King, M. D., Y. J. Kaufman, W. P. Menzel, and D. Tanre. (1992). Remote sensing of cloud, aerosol, and water vapor properties from the Moderate Resolution Imaging Spectrometer (MODIS). IEEE Trans. Geosci. Remote Sens., 30, 2-27.

Levy, R. C., Remer, L. A., Mattoo, S., Vermote, E. F., and Kaufman, Y. J. (2007). Second-generation operational algorithm: Retrieval of aerosol properties over land from inversion of Moderate Resolution Imaging Spectroradiometer spectral reflectance, J. Geophys. Res., 112, D13211, doi:10.1029/2006JD007811

Li, R., Kaufman, Y. J., Gao, B., and Davis, C. O. (2007). An Atmospheric Correction Algorithm for Remote Sensing of Bright Coastal Waters Using MODIS Land and Ocean Channels in the Solar Spectral Region, IEEE Trans. Geosci. Remote Sens., 45, 0196-2892.

Li, R., Kaufman, Y. J., Gao, B., et al. (2003). Remote sensing of suspended sediments and shallow coastal waters. IEEE Trans. Geosci. Remote Sens., 41, 559.

Mobley, C. D. (1994). Light and Water Radiative Transfer in Natural Waters. New York: Academic, pp. 80-100.

Morel, A., \& Belanger, S. (2006). Improved detection of turbid waters from ocean color sensors information. Remote Sens. Environ., 102, 237-249.

Morel, A., \& Prieur, L. (1977). Analysis of variations in ocean color. Limnol. Oceanogr., 22, 709-722.

Ramaswamy, V., Rao, P. S., Rao, K. H., Thwin, S., Rao, N. S., Raiker, V. (2004). Tidal influence on suspended sediment distribution and dispersal in the northern Andaman Sea and Gulf of Martaban. Mar. Geol., 208, 33-42

Reza, M. M. (2008). Assessment of Suspended Sediments Concentration in Surface Waters, Using Modis Images. Am. J. Appl. Sc., 5, 798-804.

Ritchie J. C. and Cooper, C. M. (1988). Comparison of Measured Suspended Sediment Concentration with Suspended Sediment Concentrations Estimated from Landsat MSS data. Int. J. Remote Sens., 9: 379-387.

Ritchie, J. C., Cooper, C. M. and Schiebe, F. R. (1990). The Relationship of MSS and TM Digital Data with Suspended Sediments, Chlorophyll and Temperature in Moon Lake, Mississippi. Remote Sens. Environ., 33: 137-148.

Ritchie, J. C., Schiebe, F. R. and McHenry, J. R. (1976). Remote Sensing of Suspended Sediments in Surface Water. Photogramm. Eng. Rem. S., 42, 1539-1545.

Wang, M., \& Shi, W. (2005). Estimation of ocean contribution at the MODIS near-infrared wavelengths along the east coast of the U.S.: Two case studies. Geophys. Res. Lett., 32, L13606, doi: 10.1029/12005GL022917.

Yu, H., et al. (2006). A review of measurement-based assessments of aerosol direct radiative effect and forcing. Atmos. Chem. Phys., 6, 613-666. 
Table 1. Main characteristics of MODIS land and ocean color channels in the visible and near infrared spectral region

\begin{tabular}{|c|c|c|c|c|}
\hline Primary use & Channels & Bandwidth $(\mathrm{nm})$ & $\begin{array}{c}\text { Maximum } \\
\text { reflectance }\end{array}$ & $\begin{array}{c}\text { Signal to noise } \\
\text { ratio }\end{array}$ \\
\hline Land/cloud & 1 & $620-670$ & 1.49 & 128 \\
& 2 & $841-876$ & 1.00 & 201 \\
& 3 & $459-479$ & 1.04 & 243 \\
& 4 & $545-565$ & 0.93 & 228 \\
& 5 & $1230-1250$ & 0.51 & 74 \\
& 6 & $1628-1652$ & 1.02 & 275 \\
& 7 & $2105-2155$ & 0.81 & 110 \\
\hline Ocean color & 8 & $405-420$ & 0.33 & 880 \\
& 9 & $438-448$ & 0.23 & 838 \\
& 10 & $483-493$ & 0.17 & 802 \\
& 11 & $526-536$ & 0.15 & 754 \\
& 12 & $546-556$ & 0.12 & 750 \\
& 13 & $662-672$ & 0.08 & 910 \\
& 14 & $673-683$ & 0.07 & 1087 \\
& 15 & $743-753$ & 0.07 & 586 \\
& 16 & $862-877$ & 0.06 & 516 \\
\hline
\end{tabular}

Table 2. Reflectance value of 0.47 and $0.55 \mu \mathrm{m}$ band. Column 5 shows the value $\log _{10}$ ratio of the bands

\begin{tabular}{|c|c|c|c|c|}
\hline Scene & Area & $0.47 \mu \mathrm{m}$ & $0.55 \mu \mathrm{m}$ & $\log 10(0.47) / \log 10(0.55)$ \\
\hline \multirow[t]{5}{*}{ Clear } & 1 & 0.088796 & 0.044630 & 0.778753 \\
\hline & 2 & 0.087905 & 0.044492 & 0.781218 \\
\hline & 3 & 0.087217 & 0.043696 & 0.779223 \\
\hline & 4 & 0.087946 & 0.043592 & 0.775976 \\
\hline & 5 & 0.088108 & 0.044665 & 0.781451 \\
\hline \multirow[t]{5}{*}{ Haze } & 6 & 0.114022 & 0.064697 & 0.793034 \\
\hline & 7 & 0.106005 & 0.056636 & 0.78167 \\
\hline & 8 & 0.111674 & 0.060303 & 0.780583 \\
\hline & 9 & 0.104507 & 0.064351 & 0.823247 \\
\hline & 10 & 0.107058 & 0.061341 & 0.800478 \\
\hline \multirow[t]{5}{*}{ Sediment } & 11 & 0.106045 & 0.105971 & 0.999689 \\
\hline & 12 & 0.111066 & 0.108289 & 0.988609 \\
\hline & 13 & 0.100498 & 0.080715 & 0.912901 \\
\hline & 14 & 0.104547 & 0.105833 & 1.005444 \\
\hline & 15 & 0.105357 & 0.098671 & 0.971691 \\
\hline
\end{tabular}


22 NOVEMBER 2008

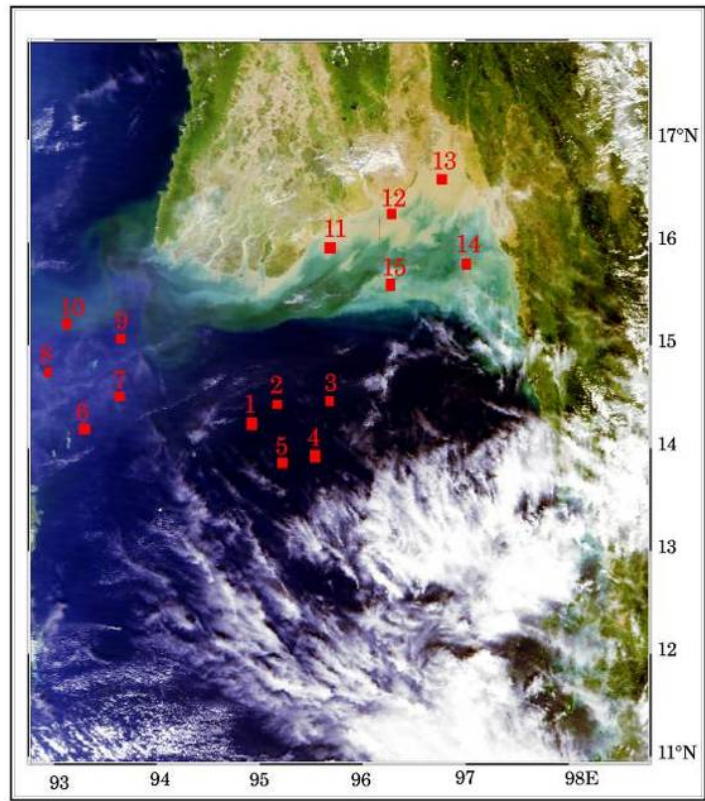

(a)
22 NOVEMBER 2008

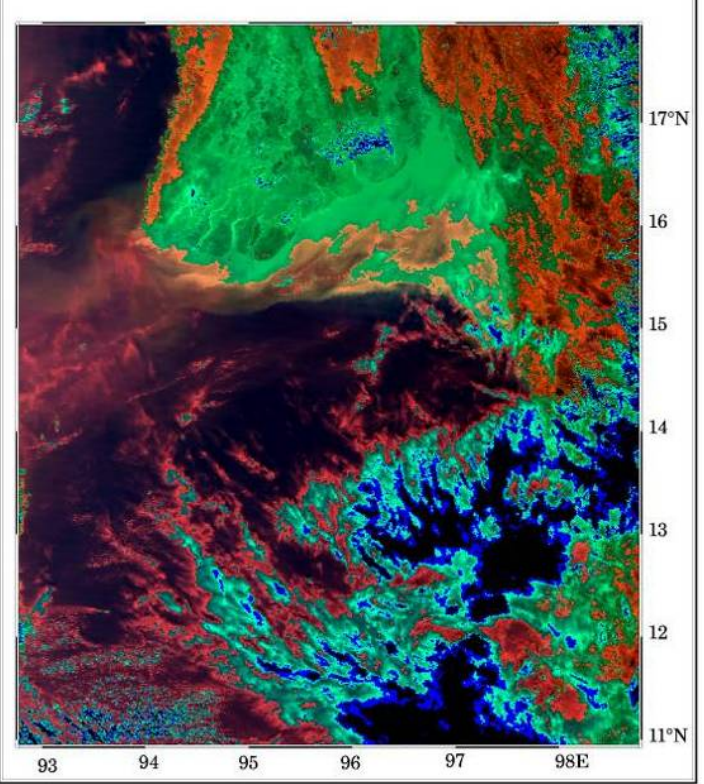

(b)

Figure 1. Image of MODIS channels for 22 November 2008. (a) RGB image (red: channel 1, green: channel 4, blue: channel 3) of MODIS aerosol channels and (b) Composite image (red: channel 14, green: channel 12, blue: channel 10) of ocean color channels.

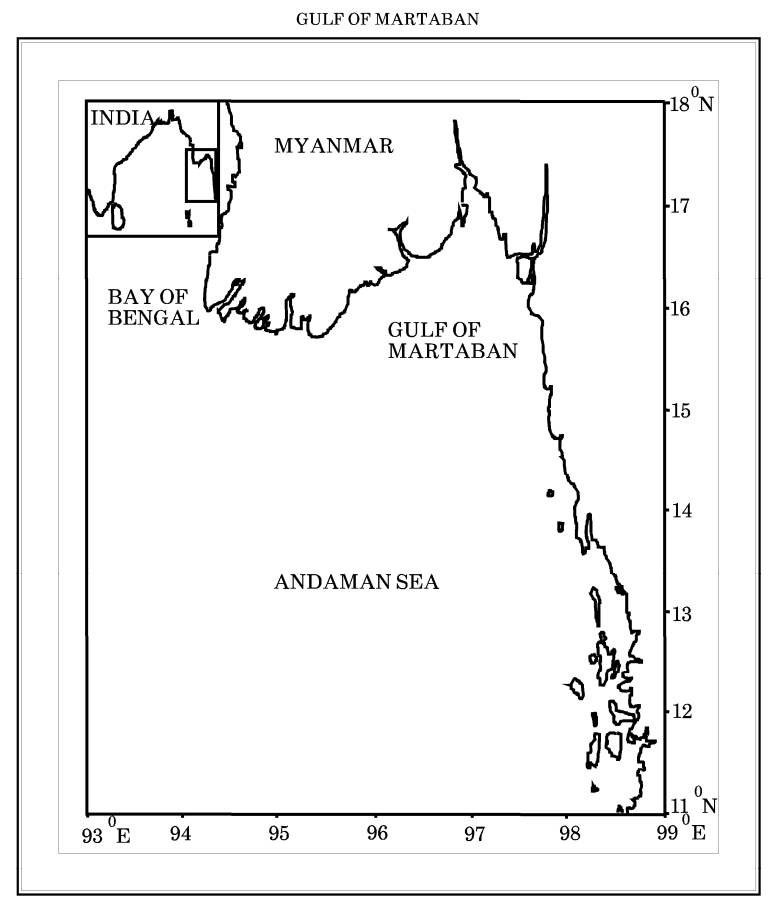

Figure 2. Study area map 


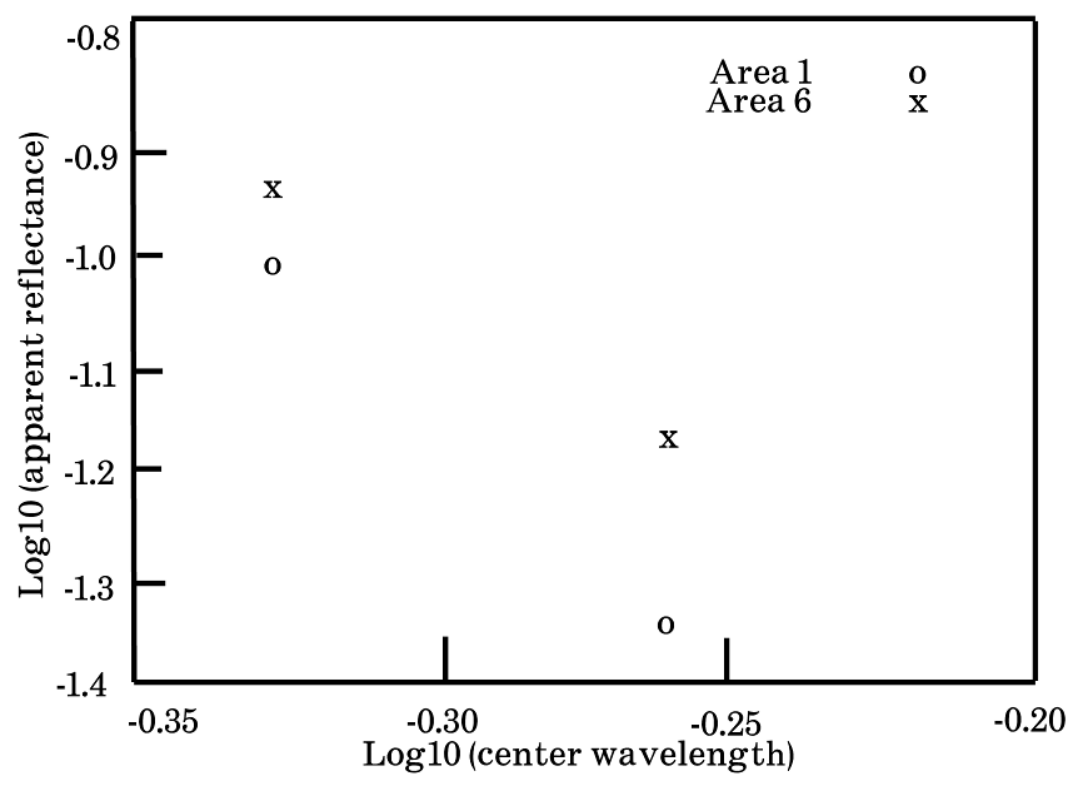

(a)

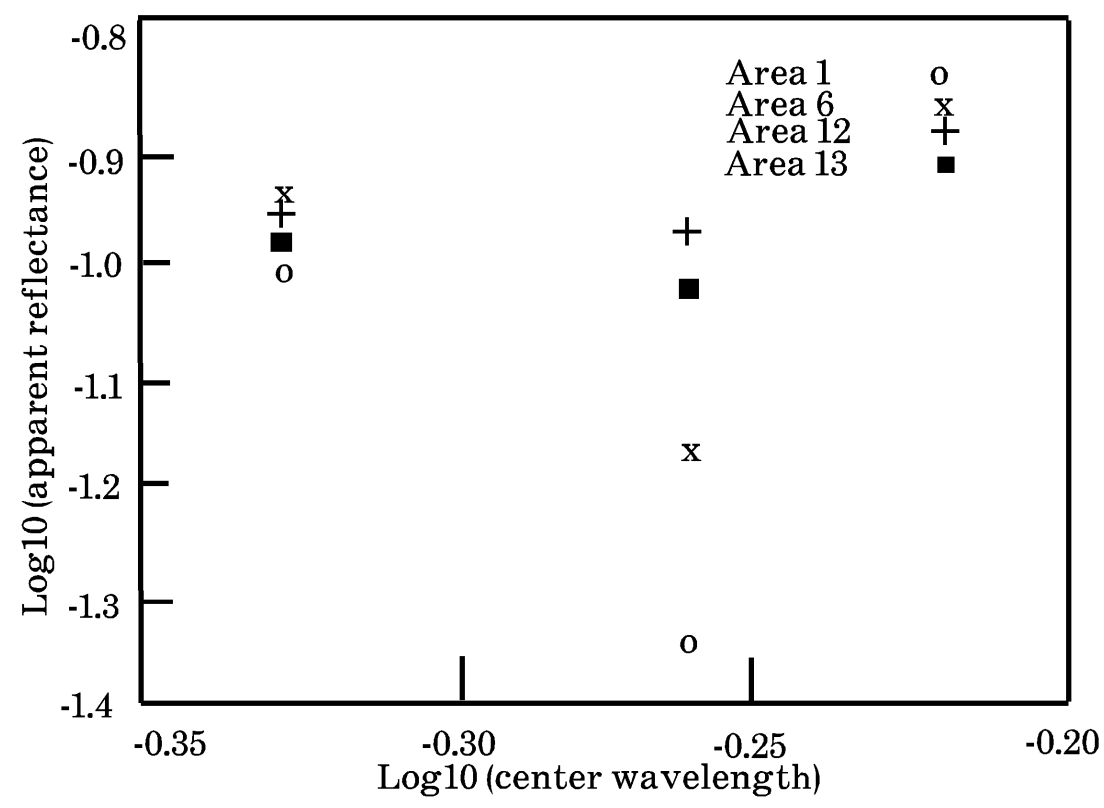

(b)

Figure 3. $\log _{10}$ (reflectance) of clear, hazy and turbid areas against $\log _{10}$ (center wavelength). (a) Plot of the $\log _{10}$ (reflectance) as a function of $\log _{10}$ (center wavelength) for clear water areas (areas 1 and 6, marked in Fig. 1(a)) and (b) similar plot for the turbid water areas 12 and 13, as marked in Fig. 1(a). 


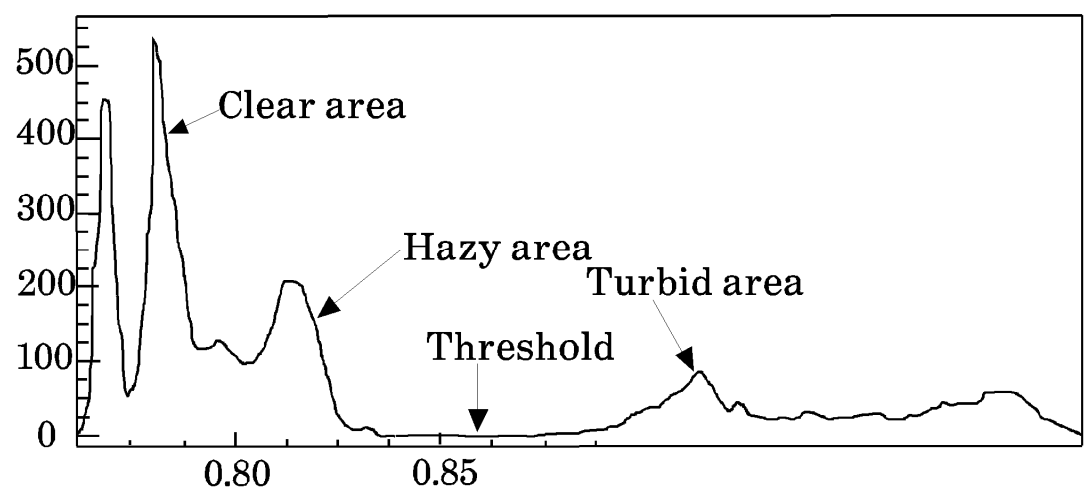

Figure 4. Histogram for 22 November 2008 image. Clear, hazy and turbid areas are clearly separated in this histogram. The threshold to distinguish turbid and clear areas is taken as 0.86

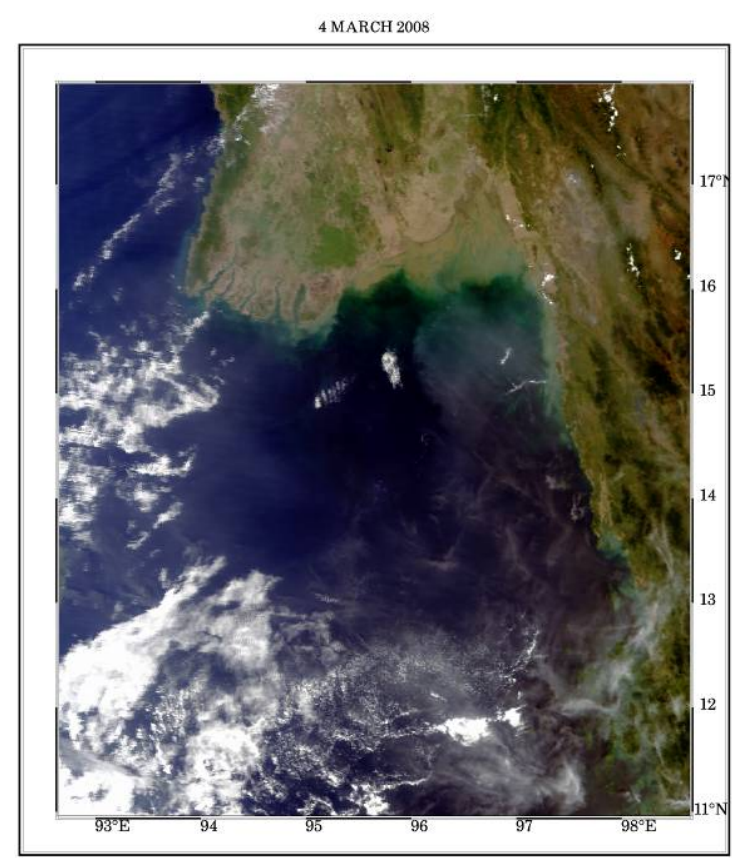

RGB

(a)

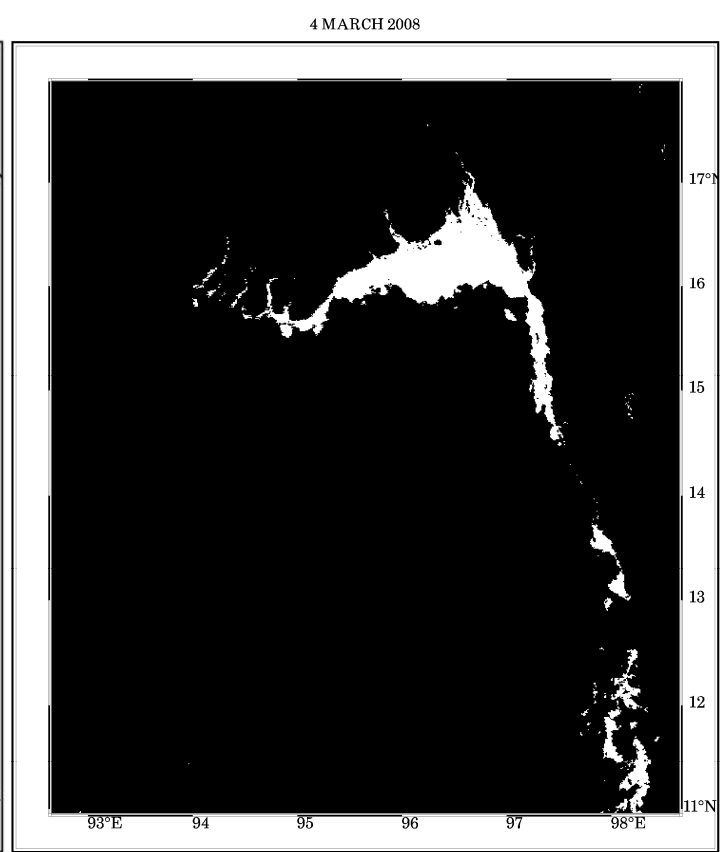

$\log _{10}$ ratio algorithm

(b)

Figure 5. The true color (a) and masked images (b) of Gulf of Martaban acquired on 4 March 2008. White color shows turbid area (b). 


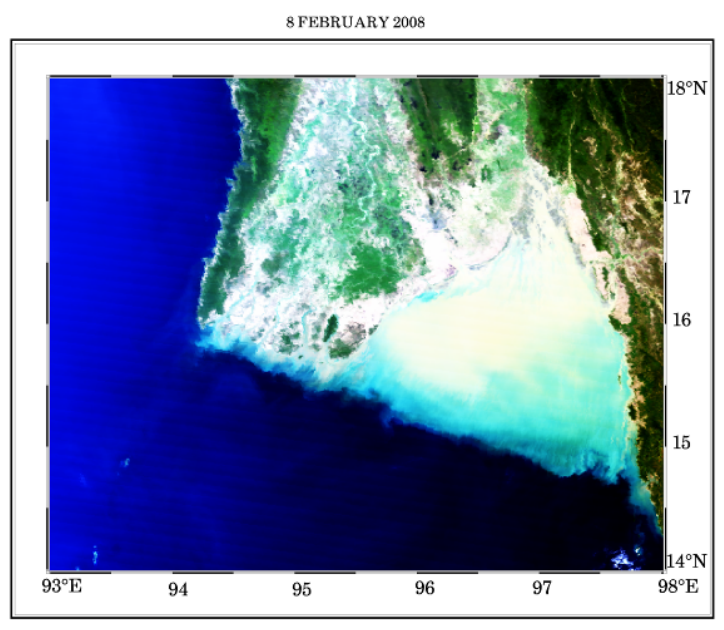

(a) RGB

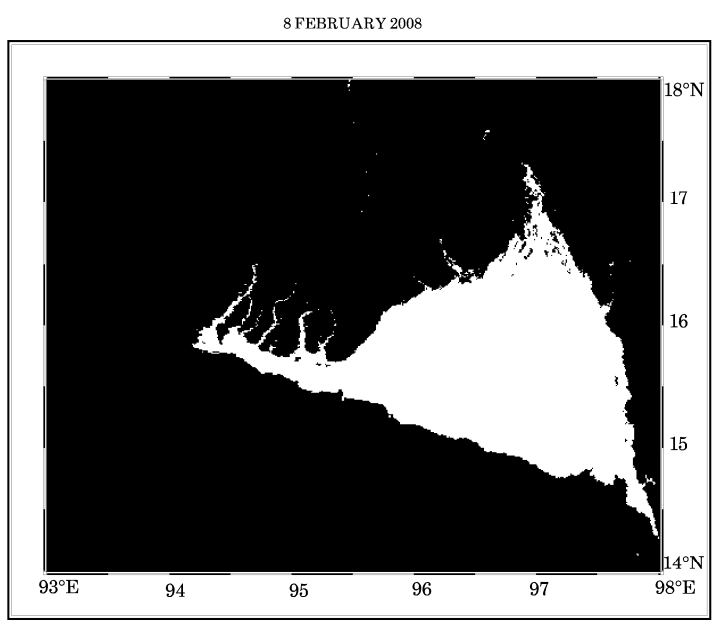

(b) $\log _{10}$ ratio algorithm

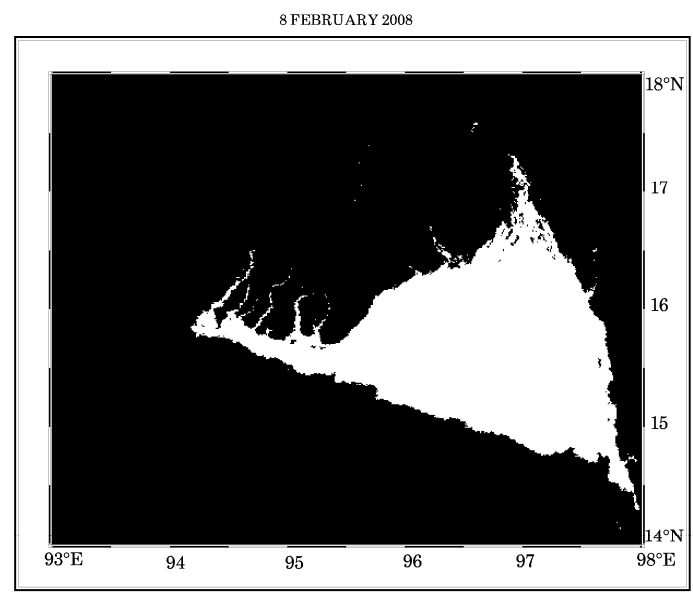

(c) Li et al. (2003) algorithm

Figure 6. True color and masked image of Gulf of Martaban acquired on 8 February 2008. (a) RGB image (red: channel 1, green: channel 4, blue: channel 3), (b) masked image computed using $\log _{10}$ ratio and (c) masked image generated by Li et al. (2003) proposed algorithm. White shades represent turbid and shallow water areas. 